\title{
CALCULATION OF ELECTROSTATIC PRECIPITATOR PARAMETERS FOR LARGE POULTRY ENTERPRISE
}

\author{
Alexander Lysakov, Gennady Nikitenko, Vitaly Grinchenko, Valentina Avdeeva \\ Stavropol State Agrarian University, Russia \\ s_lysakov@mail.ru, nikitenko_gv@mail.ru,grinchen_ko@mail.ru, avdeeva_vn@mail.ru
}

\begin{abstract}
Electrostatic precipitators are used in industrial enterprises for waste gas collection. Their implementation prevents air pollution. Electrostatic precipitators charge the gas particles and make them gather on the collection plates. The electrostatic precipitator in the poultry houses can hold $90-95 \%$ of dust and 80 $85 \%$ of microorganisms. The electrostatic precipitator use in agriculture is limited due to their costs. For example, a 6 percents increase in the extent of purification increases their relative cost by almost 3 times. To reduce the cost, the charging region number should be reduced to no more than two, and more precise determination of electrostatic precipitator parameters should be made. The article presents the calculations used to determine the critical electric field, initial voltage, specific current, and ion specific number for a two-stage electrostatic precipitator. The calculation was made with mathematical model methods in a software product developed by the authors and intended for the electrostatic precipitator parameter determination. As a result of the theoretical calculations, it was established that with the increase in specific current the ion specific number increases; an increase in the ion specific number resulted in an increase in the extent of purification of the electrostatic precipitator. The parameters of the volt-ampere characteristics were also determined, at which the extent of purification of the poultry farm premises was in the range of 95-99\%.
\end{abstract}

Keywords: collecting electrode, electrostatic precipitator, ecology.

\section{Introduction}

A two-stage electrostatic precipitator is designed for purification of the inflowing air and the air inside the poultry houses. The particles get charged in the filter and precipitate in different structure zones. The parameters of the two-stage electrostatic precipitator are: power voltage of electrodes 6-15 $\mathrm{kV}$; power consumption 10-30 W for the air flow rate of $1000 \mathrm{~m}^{3} \cdot \mathrm{h}^{-1}$; air speed in the filter section $2 \mathrm{~m} \cdot \mathrm{sec}^{-1}$, resistance to air-flow 10-50 Pa. Electrostatic precipitators collect $90-95 \%$ of dust and 80$85 \%$ of microorganisms [1-3].

Currently, there are a lot of multiple-purpose devices for the air purification, however, they all are designed for the industrial consumers and cannot provide the necessary cleanness in the poultry enterprises. The leaders among them are the electrostatic precipitators able to collect the particles with a size of 1 micron and more and saturate the air with useful ions. The wide use of electrostatic precipitators is limited due to the high voltage applied (10 kV and more) and their high cost, since the increase in the purification degree at $6 \%$ provides an almost triple increase in their relative cost [4-6].

The critical voltage $U_{0}$ initiates the corona discharge in the electrostatic precipitator. With the increase in the voltage on the electrodes over the critical value, the electrostatic field strength increases in the inter-electrode space, and consequently, the corona current increases. With that, in the properly operating electrostatic precipitator, the processes of particle charging and collecting becomes more intensive, thus, the collecting efficiency increases. However, the voltage on the electrodes may reach the definite critical point that causes the loss of electric strength of the gas between the electrodes due to a spark discharge or an arc discharge, i.e. the breakage of the inter-electrode air occurs [7-10].

The degree of purification provided by the electrostatic precipitator depends largely on the area of the collecting electrode and the speed of the incoming air flow.

\section{Materials and methods}

The calculation of the parameters of the electrostatic precipitator starts with the selection of the corona discharge (Fig. 1).

The intensity of electrostatic field at which the corona discharge occurs is called critical and can be calculated with the formula (1):

$$
E_{0}=30.3 \cdot \rho\left(1+\frac{0.0298}{\sqrt{\rho \cdot r_{0}}}\right)
$$


where $E_{0}$ - critical intensity of the corona discharge, $\mathrm{V} \cdot \mathrm{m}^{-1}$;

$\rho$ - relative air density, $\mathrm{kg} \cdot \mathrm{m}^{-3},\left(\right.$ normally, $\left.\rho_{0}=1.29 \mathrm{~kg} \cdot \mathrm{m}^{-3}\right)$;

$r_{0}$ - radius of the corona electrode, $\mathrm{m}$.
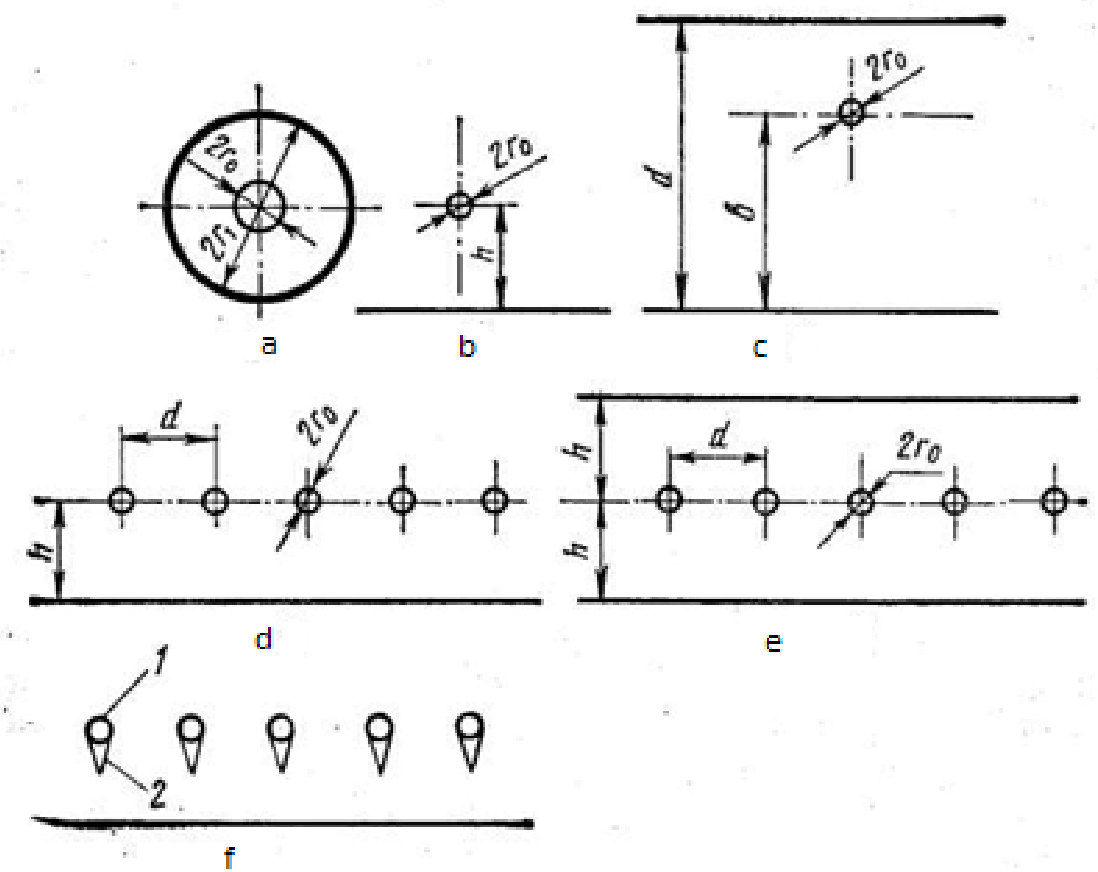

$\mathrm{e}$

Fig. 1. Electrode system for creation of the corona discharge field: a - wire on the cylinder axis; $\mathrm{b}$ - wire - plate; c - wire between two plates; $\mathrm{d}$ - set of wires-plate; $\mathrm{e}$ - set of wires between the plates; $\mathrm{f}$ - set of rods with needles - plate; 1 - a rod; 2 - a needle

It follows from the formula that the critical intensity of the electrostatic field does not depend on the electrode system, but on the corona dimensions and the weather conditions.

The initial voltage, $\mathrm{V}$, of the corona discharge can be found with the following formula (2):

$$
U_{0}=E_{0} \cdot r_{0} \cdot A \text {, }
$$

where $A-$ function of geometric parameters of this electrode system.

During the increase in voltage, the formula of the volt-ampere characteristic (VAC) of the corona discharge is as follows:

$$
I_{l}=\varepsilon_{0} \cdot k \cdot G,
$$

where $I_{l}$ - specific (per unit of length of the corona wire) current strength, A $\cdot \mathrm{m}^{-1}$;

$\varepsilon_{0}-$ electric constant $\left(\varepsilon_{0}=8.85 \cdot 10^{-12} \mathrm{~F} \cdot \mathrm{m}^{-1}\right)$;

$k$ - ratio of the average speed of the directed motion of ions to the electric field intensity, called the ion mobility, $\mathrm{m}^{2} \cdot(\mathrm{V} \cdot \mathrm{s})^{-1}$;

$G$ - function of voltage and geometric parameters of this electrode system, $\mathrm{V}^{2} \cdot \mathrm{m}^{-2}$.

The number of air ions, ion $\mathrm{m}^{-1}$, produced on one unit of length of the corona wire electrode is found with the formula (4):

$$
n_{l}=\frac{I_{l}}{e},
$$

where $e$-charge of the air ion, $\mathrm{C}\left(e=1.6 \cdot 10^{-19} \mathrm{C}\right)$.

During the electro-filter operation, the number of air ions should increase with the increase in the processed air volume. 


\section{Results and discussion}

The calculation of the electrostatic precipitator parameters was made for the electrode system shown in Figure 1.a. In the software product developed by the authors, the critical intensity $E_{0}$, the initial voltage $U_{0}$, the volt-ampere characteristic, and the number of air ions were calculated. The corona electrode radius was $0.15 \cdot 10^{-3} \mathrm{~m}$, the following voltage range was taken: $1.1 U_{0}, 1.2 U_{0}, 1.3 U_{0}$, $1.4 U_{0}, 1.5 U_{0}$. The relative air density was $\rho=1$.

The function of geometric parameters $A$ of the electrode system was found with the formula (5):

$$
A=\ln \left(\frac{r_{1}}{r_{0}}\right),
$$

where $r_{1}$-radius of the collecting electrode.

The function of the voltage and geometric parameters $G$ of the electrode system in case of changes of voltage was found with the formula (6):

$$
G=\frac{8 \pi}{r_{1}^{2}} \cdot\left(1+0.0275 \sqrt{\frac{r_{1}}{r_{0}}}\right) \cdot U \cdot\left(U-U_{0}\right),
$$

where $U$ - voltage of corona discharge, $\mathrm{V}$

If $U=U_{0}$, the function is $\mathrm{G}=0$, therefore the corona discharge current is $I_{l}=0$.

Other results of the calculations of the electric precipitator parameters in case of change of voltage, as well as the distance between the electrodes are given in Tables 1-2.

Table1

Data for calculation of parameters of the electrostatic precipitators for the electrode system "wire on the cylinder axis"

\begin{tabular}{|c|c|c|c|}
\hline $\boldsymbol{r}_{\mathbf{0}} \cdot \mathbf{1 0}^{-\mathbf{3}}, \mathbf{m}$ & $\boldsymbol{r}_{\mathbf{1}} \cdot \mathbf{1 0}^{-2}, \mathbf{m}$ & $\boldsymbol{A}$ & $\boldsymbol{U}_{\mathbf{0}} \cdot \mathbf{1 0} \mathbf{3}, \mathbf{V}$ \\
\hline 0.15 & 5 & 5.81 & 9.07 \\
\hline 0.15 & 10 & 6.5 & 10.14 \\
\hline 0.15 & 15 & 6.9 & 10.77 \\
\hline 0.15 & 20 & 7.2 & 11.23 \\
\hline
\end{tabular}

Table 2

Calculation of parameters of the electrostatic precipitator for the electrode system "wire on the cylinder axis"

\begin{tabular}{|c|c|c|c|c|c|}
\hline \multicolumn{7}{|c|}{$k=2.1 ; r_{1}=5 \cdot 10^{-2} \mathrm{~m}, A=5.81$} \\
\hline$U_{0}=9.07 \cdot 10^{3} \mathrm{~V}$ & $U=1.1 U_{0}$ & $U=1.2 U_{0}$ & $U=1.3 U_{0}$ & $U=1.4 U_{0}$ & $U=1.5 U_{0}$ \\
\hline$U, \cdot 10^{3}, \mathrm{~V}$ & 9.977 & 10.884 & 11.791 & 12.698 & 13.605 \\
\hline$G$ & 2350659 & 5128899 & 8334201 & 11967084 & 16027549 \\
\hline$I_{l}, \mathrm{~A} \cdot \mathrm{m}^{-1}$ & 0.437 & 0.953 & 1.55 & 2.22 & 2.98 \\
\hline$n_{l}$, ion $\cdot \mathrm{m}^{-1}$ & $273.1 \cdot 10^{16}$ & $595.6 \cdot 10^{16}$ & $970 \cdot 10^{16}$ & $1388 \cdot 10^{16}$ & $1863 \cdot 10^{16}$ \\
\hline \multicolumn{7}{|c|}{$k=1.4 ; r_{1}=20 \cdot 10^{-2} \mathrm{~m}, A=7.2$} \\
\hline$U_{0}=11.23 \cdot 10^{3} \mathrm{~V}$ & $U=1.1 U_{0}$ & $U=1.2 U_{0}$ & $U=1.3 U_{0}$ & $U=1.4 U_{0}$ & $U=1.5 U_{0}$ \\
\hline$U, \cdot 10^{3}, \mathrm{~V}$ & 12.35 & 13.48 & 14.6 & 15.72 & 16.85 \\
\hline$G$ & $2.4 \cdot 10^{5}$ & $5.3 \cdot 10^{5}$ & $8.6 \cdot 10^{5}$ & $12.2 \cdot 10^{5}$ & $16.5 \cdot 10^{5}$ \\
\hline$I_{l}, \cdot 10^{-3} \mathrm{~A} \cdot \mathrm{m}^{-1}$ & 29.76 & 65.72 & 106.6 & 151.3 & 204.6 \\
\hline$n_{l}$, ion $\cdot \mathrm{m}^{-1}$ & $18.6 \cdot 10^{16}$ & $41.1 \cdot 10^{16}$ & $66.7 \cdot 10^{16}$ & $94.5 \cdot 10^{16}$ & $128 \cdot 10^{16}$ \\
\hline
\end{tabular}

The data in Tables 1-2 allow the conclusion, that in case of increase of the distance between a corona electrode and a collecting electrode in the pipe-type electric precipitator (Fig. 1.a), the initial voltage of the discharge increases, both the current of the discharge and the number of ions decrease. Moreover, there is a risk of breakdown of the corona discharge with its transformation to the arc or spark discharge. 
Also, the parameters of the plate-type electrostatic precipitator were calculated, its diagram is shown in Fig.1.d. The critical field strength, initial voltage, specific current, specific number of ions were identified. The parameters of the plate electrodes system were calculated as follows:

$$
\begin{gathered}
A=\left(\frac{\pi \times h}{d}\right)-\ln \left(\frac{2 \pi \times r_{0}}{d}\right), \\
G=\frac{2 \pi^{3} \times B}{h^{2}} \times\left(\frac{U_{0}}{A}\right)^{2-C} \times\left(U-U_{0}\right)^{C},
\end{gathered}
$$

where $h$-distance between the corona and the collecting electrodes, m;

$d$-distance between the corona electrodes, $\mathrm{m}$;

$r_{0}$ - radius of the corona electrode, $\mathrm{m}$;

$B, C$ - extra factors of the electrode system.

$\mathrm{C}$ and $\mathrm{B}$ factors are calculated with the following formulas:

$$
\begin{gathered}
B=0.115 \frac{d}{h}+0.125 \text { if } 0.5 \leq \frac{h}{d} \leq 1.3, \\
B=0.0178 \frac{h}{d}+0.185 \text { if } 1.3 \leq \frac{h}{d} \leq 2.3, \\
C=1.6-0.14 \frac{h}{d} .
\end{gathered}
$$

With changes of $h, d$ parameters, the voltage values from $1.1 U_{0}$ to $1.4 U_{0}$, the current value and number of ions were calculated (Table 3 ).

Calculation of parameters of the electrostatic precipitator for the electrode system

"set of wires in the middle between two plates"

\begin{tabular}{|c|c|c|c|c|}
\hline \multicolumn{6}{|c|}{$d=h=5 \cdot 10^{-2}, k=2.3 ; r_{0}=0.15 \cdot 10^{-3} m, A=6.42 ; B=0.24 ; C=1.46$} \\
\hline$U_{0}=20 \cdot 10^{3} \mathrm{~V}$ & $U=1.1 U_{0}$ & $U=1.2 U_{0}$ & $U=1.3 U_{0}$ & $U=1.4 U_{0}$ \\
\hline$U, \cdot 10^{3}, \mathrm{~V}$ & 22 & 24 & 26 & 28 \\
\hline $\mathrm{G} \cdot 10^{10}$ & 3.04 & 8.3 & 15.2 & 23 \\
\hline$I_{l} \cdot 10^{-3}, \mathrm{~A} \cdot \mathrm{m}^{-1}$ & 0.61 & 1.66 & 3.04 & 4.6 \\
\hline$n_{l}$, ion $\cdot \mathrm{m}^{-1}$ & $381 \cdot 10^{16}$ & $1038 \cdot 10^{16}$ & $1900 \cdot 10^{16}$ & $2875 \cdot 10^{16}$ \\
\hline$h=5 \cdot 10^{-2}, d=10 \cdot 10^{-2}, k=2.3 ; r_{0}=0.15 \cdot 10^{-3}$ & $m, A=5.54 ; B=0.355 ; C=1.53$ \\
\hline$U_{0}=17.3 \cdot 10^{3} \mathrm{~V}$ & $U=1.1 U_{0}$ & $U=1.2 U_{0}$ & $U=1.3 U_{0}$ & $U=1.4 U_{0}$ \\
\hline$U, 10^{3}, \mathrm{~V}$ & 19.02 & 20.75 & 22.48 & 24.21 \\
\hline $\mathrm{G} \cdot 10^{4}$ & 34.7 & 100.2 & 186.4 & 289.5 \\
\hline$I_{l} \cdot 10^{-8}, \mathrm{~A} \cdot \mathrm{m}^{-1}$ & 707.88 & 2044.1 & 3802.6 & 5905.8 \\
\hline$n_{l}$, ion $\cdot \mathrm{m}^{-1}$ & $442 \cdot 10^{11}$ & $1278 \cdot 10^{11}$ & $2377 \cdot 10^{11}$ & $3691 \cdot 10^{11}$ \\
\hline
\end{tabular}

Table 3 presents the most optimal parameters of the electrostatic precipitator related to the current, voltage and the number of ions. The comparison of the parameters from Tables 2 and 3 provides the information about the operation modes of the electrostatic precipitator. For the safe run of the electrostatic precipitator, the specific current strength should be as little as possible. The minimum value of the specific current strength is $5905.8 \cdot 10^{-8} \mathrm{~A} \cdot \mathrm{m}^{-1}$ for the electrostatic precipitator with a scheme "a set of wires in the middle between two plates".

This value allows regulating of the corona discharge by changing the voltage or the distance between the corona electrodes without the risk of corona failure or corona breakdown.

The electrode system of the electrostatic precipitator "a set of wires in the middle between two plates" is more profitable than the electrode system "a wire on the cylinder axis". This design of the electric precipitator is the most optimal for air purification in the poultry houses. 


\section{Conclusions}

On the results of the modelling of the electrostatic precipitator parameters, it was concluded that:

1. The calculation of the parameters of the electrostatic precipitator was made for two electrode systems: "a set of wires in the middle between two planes" and " a wire on the cylinder axis";

2. The calculation was made for the critical strength $E_{0}$, initial voltage $U_{0}$, volt-ampere characteristics, specific electric current and the amount of air ions.

3. The minimum value of the specific electric current for the electrode system " a wire on the cylinder axis" is $204.6 \cdot 10^{-3} \mathrm{~A} \cdot \mathrm{m}^{-1}$, this value is not safe for the electrostatic precipitator run, since it may cause a breakdown of the inter-electrode space and the electrode damage;

4. The specific electric current value of $5905.8 \cdot 10^{-8} \mathrm{~A} \cdot \mathrm{m}^{-1}$ corresponds to the electrode system "a set of wires in the middle between two plates", it is safe for the electrostatic precipitator run, it does not cause a breakdown of the inter-electrode space and the electrode damage;

5. The electrode system of the electrostatic precipitator "a set of wires in the middle between two plates" is more effective, than the electrode system " a wire on the cylinder axis", since it has the less value of the specific electric current.

\section{References}

[1] Wang D., Wang Y., Shi Y., Yu Y. Optimization of casing wall design for electrostatic precipitators. Environmental Engineering and Management Journal, vol. 12(9), 2013, pp. 18791883.

[2] Shui T., Shen H., Yang X., Ma H., Nie X., Zhou L., Liu L. PM2.5 filtration performance of electret air filter in office buildings. Chinese Journal of Environmental Engineering, vol. 9(6), 2015, pp. 2933-2940.

[3] Chang C.-L., Bai H. An experimental study on the performance of a single discharge wire-plate electrostatic precipitator with back corona. Journal of Aerosol Science, vol. 30(3), 1999, pp. 325340.

[4] Jaworek A., Krupa A., Czech T. Modern electrostatic devices and methods for exhaust gas cleaning: A brief review. Journal of Electrostatics, vol. 65(3), 2007, pp. 133-155.

[5] Katatani A., Hosono H., Murata H., Mizuno A. Collection performance of an electrostatic precipitator using bipolar corona discharges. Proceedings of the 2012 Electrostatic Joint Conference, 2012, Cambridge, ON, Canada, June 12-14, ESA2012 e-proceedings S36, 1-5.

[6] Kim H.-J., Han B., Oda T., Hwang K.-D., Oh W.-S., Yoo S.-Y. Fine particle removal performance of a two-stage wet electrostatic precipitator using a nonmetallic pre-charger. Journal of the Air and Waste Management Association, vol. 61(12), 2011, pp. 1334-1343.

[7] Kuroda Y., Kawada Y., Takahashi T., Ehara Y., Ito T., Zukeran A., Kono Y. Effect of electrode shape on discharge current and performance with barrier discharge type electrostatic precipitator. Journal of Electrostatics, vol. 57 (3-4), 2003, pp. 407-415.

[8] Miller J., Hoferer B., Schwab A.J. The impact of corona electrode configuration on electrostatic precipitator performance. Journal of Electrostatics, vol. 44 (1-2), 1998, pp. 67-75.

[9] Mizuno A. Electrostatic precipitation. IEEE Transactions on Dielectrics and Electrical Insulation, vol. 7(5), 2000, pp. 615-624.

[10]Lysakov A., Nikitenko G., Konoplev E., Grinchenko V. Method to increase cleaning degree of electrostatic air cleaner. Proceedings of International conference «Engineering for Rural Development», 2018, pp. 554-559. 